\title{
Medication Counseling Practices in Medicine Retail Outlets Found in Bench Sheko Zone, Southern Nations, Nationalities, and Peoples' Region, South West Ethiopia
}

\author{
Fikadu Ejeta (D) \\ Diriba Feyisa (D) \\ Oliyad Kebede (1D' \\ Temesgen Aferu (iD) \\ Jafer Siraj $\mathbb{B D}^{2}$ \\ Desalegn Feyissa $\mathbb{D}^{3}$ \\ Emebet Wodajo ${ }^{3}$ \\ Alemu Tamiru ${ }^{3}$ \\ 'Department of Pharmaceutics and Social \\ Pharmacy, School of Pharmacy, College of \\ Medicine and Health Sciences, Mizan-Tepi \\ University, Mizan-Aman, Ethiopia; \\ ${ }^{2}$ Department of Pharmacology and \\ Pharmaceutical Chemistry, School of \\ Pharmacy, College of Medicine and \\ Health Sciences, Mizan-Tepi University, \\ Mizan-Aman, Ethiopia; ${ }^{3}$ Department of \\ Clinical Pharmacy and Pharmacy Practice, \\ School of Pharmacy, College of Medicine \\ and Health Sciences, Mizan-Tepi \\ University, Mizan-Aman, Ethiopia
}

\begin{abstract}
Objective: The objectives of this research were to investigate pharmacy professionals' counseling practices as well as to evaluate pharmacy professionals' counseling skills and the content of counseling services provided to patients visiting medicine retail outlets.

Methods: A facility-based observational cross-sectional study was used to assess medication counseling practice by pharmacy professionals. Data were gathered through an observation and a semi-structured questionnaire. Epi data version 4.0.2 was used to enter data, which was subsequently exported to SPSS version 21.0 for analysis. ANOVA and post hoc statistical analyses were used to investigate the association between independent and dependent variables; and a 0.05 p-value was considered.

Results: This study has a total of 105 pharmacy professionals that were included in the analysis. The majority of those who responded were between the ages of 25 and 29. The most common drug information offered by pharmacy staff to patients was frequency of administration (90\%), length of therapy (90\%), and unit dose dispensed, according to the current study (86\%). Pharmacy professionals' age was significant on components of counseling practice as on mentioning the name of drugs during dispensing the medication $(p=0.000)$, the route of administration $(\mathrm{p}=0.000)$, a drug dose $(\mathrm{p}=0.003)$, frequency of drug administration $(p=0.016)$, proper medicine storage $(p=0.024)$, type of dosage form $(p=0.025)$, and duration of treatment $(\mathrm{p}=0.012)$. In comparison with the other age groups, an age greater than 40 years was significant on components of counseling practice $(p=0.001)$ as a factor associated with penurious counseling practice than the other groups.

Conclusion: This study shows that counseling practice is still quite low in comparison to what is expected. Some of the issues that affect counseling include a high patient load, the lack of a private counseling room, a lack of updated drug knowledge, and a lack of experience were factors that influence counseling.
\end{abstract}

Keywords: counselling, counselling practice, medication, pharmacy professionals, MizanAman, Southwest Ethiopia

\section{Introduction}

Medication counseling is an important component of pharmaceutical care. The importance of medication counseling in pharmaceutical care cannot be overstated. Medication counseling at the point of delivery is a pharmacy professional's function that can significantly improve medication safety and patient adherence, potentially avoiding treatment failure and resource waste. ${ }^{1}$ The pharmacist can assist patients
Correspondence: Fikadu Ejeta

Tel +251910136034

Email fikaduejeta@gmail.com 
in preventing medication misshapes and latent errors. It also should include an evaluation of whether or not medication counseling is delivered effectively as intended and how the patients understand and use the information to improve the likelihood of the desired treatment outcomes. Oral medication counseling is commonly provided as part of patient counseling and along with written information for the patients to refer to when they need it elsewhere. ${ }^{2}$ Patients may be unable to focus on what the pharmacy professionals are saying to them because they are often agitated and disturbed by illness when taking their prescription. Written materials re-inform what the pharmacy professionals say and assist the patient to easily remember what was said. The written materials may provide the answer or encourage the patient to know if the patient has forgotten or is unclear about what the pharmacist said. $^{3}$

Counseling could be described as the provision of advice pertinent to the medication between a pharmacy professional and a patient and/or a caregiver. It is a guide on how the intended information to be delivered and received, and the patient's understanding and use of this information to attain the intended therapeutic outcomes. ${ }^{4}$ In pharmaceutical care processes, patient counseling is the final stage which ensures the supply of correct medicine to the correct patients. ${ }^{5}$

Medication counseling is commonly delivered through oral speech or in written forms to the patients. It contains an introduction, process, and conclusion. ${ }^{6}$ The goal of medication counseling is to assure and confirm how the patient understands the information and to reassure and verify the patient's understanding if there is any ambiguity based on their feedback. ${ }^{7}$

Depending on the type of drug, the patient should be advised in a quiet or semi-private environment away from other people. ${ }^{8}$ This provides an opportunity for the patient to ask inquiries. Consistent and properly implemented medication counseling will improve patient medication understanding. More attention will be provided to the patients who are most in need. Pharmacists can promote greater patient loyalty not only through professionalism but also through greater relational skills. ${ }^{9}$ Patients using new drugs under active surveillance by food and drug authorities, drugs with special storage conditions, those with complicated directions, those with additional warning labels, and those who are alcohol contraindicated will always relive additional verbal or written information. ${ }^{10}$
More than half of all drugs are prescribed or delivered incorrectly all over the world. ${ }^{11}$ More than half of all patients, on the other hand, fail to take their prescription as prescribed. Inappropriate drug use can squander resources, necessitate patient out-of-pocket payments, and cause severe patient harm in the form of poor treatment outcomes and hazardous drug interactions. ${ }^{12}$ Despite the fact that competent and clear counseling is an important part of pharmacy service provided by pharmacists, it has received less attention in Ethiopia. It is thought that a lack of pharmacy professional preparedness, a paucity of competent employees, and public perceptions about practicing pharmacists have all played a role in the current clinical practice challenges. ${ }^{13}$ Pharmacists must concentrate a higher emphasis on patient counseling in order to improve patient health care and prevent medication-related errors. Even when manpower cannot match the needs of rising prescription volume, pharmacists must nevertheless spend time educating patients in order to deliver improved patient care. ${ }^{14}$ To date, there is a paucity of data regarding the quality of counseling services delivered to patients in medicine retail outlets in Bench-Sheko Zone of Southern nations and nationalities of Southwest Ethiopia. This study aims to fill this gap through evaluation of pharmacy professionals' counseling practices as well as to evaluate pharmacy professionals' counseling skills and the content of counseling services provided to patients visiting those medicine retail outlets. Hoping this would identify the strengths and weaknesses of counseling practices in medicine retail outlets and, as a result, improving pharmaceutical care service.

\section{Methods}

\section{Study Area and Period}

This study was carried out in the Bench Sheko zone from January to March 2021.

\section{Study Design, Population, and Sampling Technique}

A facility-based observational cross-sectional study was used to assess medication counseling practice by pharmacy personnel. Convenience sampling technique was employed. All pharmacy professionals (this includes pharmacists, pharmacy technicians and health assistants) who work in medicine retail outlets in the zone were the source population and those who fulfilled the eligibility criteria were the study population. Pharmacists are degree holders 
in the field of Pharmacy and druggists are diploma holders according to the Ethiopian educational curriculum.

\section{Eligibility Criteria Inclusion Criteria}

Functional drug retail outlets during the data collection period.

Pharmacy professionals who volunteered during the data collection period.

\section{Exclusion Criteria}

Closed drug retail outlets during the data collection period.

Pharmacy professionals who were not volunteered to respond.

\section{Study Variables}

\section{Independent Variables}

The independent variables included in this study are age, sex, educational qualification, experience, average hours spent, drug retail open days per week, having assistance in drug retail outlet, prescriptions dispensed per week, place medicine information provided, preferred medication counselling methods, reasons for delivering verbal information only, and average time spent on counselling.

\section{Dependent Variables}

Components of counseling and activities of counseling practice were dependent variables.

\section{Sample Size}

All pharmacy professionals working in medicine retail outlets (ie rural drug vendors, drug stores, community pharmacies, and private and governmental health institution drug retail outlets) in the zone were included in the study according to the inclusion criteria.

\section{Data Collection Process and Analysis Data Collection Instruments}

Observation was used to collect data during the study period (data collectors observed counselling activities and then filled the questionnaire under supervision of investigators), and the investigators generated and modified a semi-structured questionnaire on medication counseling practices, which was designed by the World Health Organization (WHO) on how to evaluate drug usage in healthcare settings. The investigator examined a completed questionnaire for completeness, accuracy, clarity, and consistency. Then, at two drug stores, a pretest was conducted to determine the viability of the questionnaire, enhance the design, and then alter it as needed to assure the quality of the data. Two professional pharmacists were hired and instructed to gather data, and two investigators were in charge of supervising them. Two days of training on how to maintain confidentiality were provided. Data collectors were briefed on the COVID-19 preventative protocol, data collection instruments, and observation techniques. To complete the questionnaire, at least one day of data collection was required in each medicine retail outlet. Various strategies like controlling and managing incoming data and duplicate data avoidance as well as strict data entry were used to maintain the data's quality. The study's authors conveyed the highlights of the questionnaire and the study's goal to pharmacy experts in order to improve data quality. A filled questionnaire was seen for completeness, accuracy, clarity, and consistency by the investigators and necessary corrections and changes were made timely. After data collection, it was compiled and checked for its completeness, categorized, coded, and analyzed. Data was entered into Epi data version 4.0.2 and then exported to SPSS version 21.0 for analysis. A post hoc statistical test using ANOVA was performed to study the association between independent and dependent variables. In the statistical analyses, $p$-value of 0.05 and $95 \%$ confidence interval were considered. The result was presented by tables as desired.

\section{Ethical Clearance}

A formal letter was written from the School of Pharmacy, College of Medicine and Health Sciences Mizan-Tepi University with reference number $\mathrm{CP} / 013 / 13$ and was forwarded to health offices and the pharmacy professionals in medicine retail outlets found in Bench-Sheko Zone for cooperation before data collection in accordance with the Declaration of Helsinki. Moreover, written informed consent secured from respondents before data collection was undertaken. The confidentiality of the data collected from the participants was kept.

\section{Results \\ Socio-Demographic Characteristics of Pharmacy Professionals and Drug Retail Outlets}

A total of 105 pharmacy professionals participated in this study and were included in the analysis. The response rate was $100 \%$. The largest number of the respondents belonged to the 25-29 age groups (38.1\%). The males consisting 
mainly $88(83.8 \%)$ of the pharmacy professionals, while the females were $17(16.2 \%)$. Pharmacists accounted for 28 (26.7\%), druggists for $70(66.7 \%)$, and pharmacy technicians for 7 (6.7\%). Pharmacy professionals comprised of 12 (11.4\%) had 1-5 years of experience whereas the majority, $63(60 \%)$ had 6-10 years of experience. The majority, 50 $(47.6 \%)$ of the respondents worked $>56$ hours per week and respondents worked seven days in open retail outlets were $77(73.3 \%)$ as shown in Table 1 below.

A large number, 39 (37.1\%) of pharmacy professionals dispensed 100-500 prescriptions per week. The areas where pharmacy professionals normally provide drug information to their patients were private, semi-private, and non-private areas $(68.6 \%, 22.9 \%$, and $8.6 \%$ respectively). Pharmacy professionals responded that they use both verbal and written counseling methods were $84(80 \%)$, while who use verbal methods only were $15(14.3 \%)$ and those who use only written methods were $6(5.7 \%)$. The dominant reason of the respondents for not providing written information for the

Table I Socio-Demographic Characteristics of Pharmacy Professionals

\begin{tabular}{|c|c|c|c|}
\hline Variables & Classification & Frequency & Percent \\
\hline \multirow[t]{4}{*}{ Age } & $25-29$ & 40 & 38.1 \\
\hline & $30-34$ & 27 & 35.2 \\
\hline & $35-39$ & 21 & 20 \\
\hline & $>40$ & 27 & 6.7 \\
\hline \multirow[t]{2}{*}{ Sex } & Male & 88 & 83.8 \\
\hline & Female & 17 & 16.2 \\
\hline \multirow{4}{*}{$\begin{array}{l}\text { Educational } \\
\text { qualification }\end{array}$} & Pharmacist & 28 & 26.7 \\
\hline & Health & 7 & 6.7 \\
\hline & assistant & & \\
\hline & Druggist & 70 & 66.7 \\
\hline \multirow[t]{4}{*}{ Experience } & $1-5 y r s$ & 12 & 11.4 \\
\hline & $6-10 y r s$ & 63 & 60.0 \\
\hline & $11-15 y r s$ & 19 & 18.1 \\
\hline & $>15 y r s$ & II & 10.5 \\
\hline \multirow[t]{4}{*}{ Average hours spent } & $<28 \mathrm{hrs}$ & 6 & 5.7 \\
\hline & $28-42 \mathrm{hrs}$ & 16 & 15.2 \\
\hline & $42-56 \mathrm{hrs}$ & 33 & 31.4 \\
\hline & $>56 \mathrm{hrs}$ & 50 & 47.6 \\
\hline \multirow{3}{*}{$\begin{array}{l}\text { Drug retail open days } \\
\text { per week }\end{array}$} & 5 days & 8 & 7.6 \\
\hline & 6days & 20 & 19.0 \\
\hline & 7days & 77 & 73.3 \\
\hline \multirow{2}{*}{$\begin{array}{l}\text { Having assistance in } \\
\text { drug retail outlet }\end{array}$} & Yes & 94 & 89.5 \\
\hline & No & II & 10.5 \\
\hline
\end{tabular}

patients was that the pharmacy is too busy (high patient load) $67(66.7 \%)$, followed by the consumer is not interested in receiving written information $22(21.0 \%)$ and verbal information is believed to be sufficient $13(12.4 \%)$. Pharmacy professionals responded that about $51(48.6 \%)$ spent $1-2$ minutes, $26(24.8 \%)$ spent 2-5 minutes, $16(15.2 \%)$ spent more than five minutes and $12(11.4 \%)$ spent $<1$ minute, with each consumer collecting prescription medicines as the average length of time (in minutes) spent on providing verbal information to patients collecting prescription medicine by pharmacy professionals shown in Table 2 below.

As per Table 3, which was adopted from Al-Arifi ${ }^{15}$ and modified according to purpose of this study, questions used in this study were coded. During dispensing, 90 (85.7) of the professionals focus on the purpose of medication counseling they provide. To understand the information patients provided previously, pharmacy professionals around 91 (86.7) did ask how the patients understood the information about the drug that the prescriber told them. Around $88(83.8 \%)$ pharmacists asked their patients whether they had any problems taking their drugs as prescribed or dispensed. Moreover, 90 (85.5\%) of them explain what their patients would do if he/she misses a dose, as is shown in Table 4 below.

Patient counseling provides an opportunity to elicit the necessary information from a patient, and to enable safe and effective use of medicines. As a result, among the components of medication counseling, such as the name of the drug always mentioned by $56(53.3 \%)$, frequency of drug administration always by 90 (85.7\%), and proper storage always by $71(67.6 \%)$, dose of the medication always by $86(81.9 \%)$ and duration of treatment always by $90(85.7 \%)$ of these pharmacy professionals informed patients about the condition, as shown in Table 5 below. From patient conditions given special attention, pharmacy professionals gave special concern to pregnant women about 35 (33.3\%), while less concern was given to patients taking anticoagulants, 4 (3.8). From disease conditions given special attention, were given for diabetes mellitus followed by hypertension around 17 (16.2\%), and asthma about 13 (12.4\%). Pharmacy professionals gave more concern to drugs with prominent side effects around 37 (35.2\%) shown in Table 6 during counseling.

\section{Independent Variables and Factors Related to Counseling Practice}

The difference in respondents' ages, years of experience, time spent in medicine retail outlets, number of 
Table 2 Pharmacy Professionals' Observed Activities in Providing Medicine Information

\begin{tabular}{|c|c|c|c|}
\hline \multicolumn{2}{|l|}{ Variables Classifications } & \multirow{2}{*}{$\frac{\text { Frequency }}{28}$} & \multirow{2}{*}{$\begin{array}{c}\text { Percent } \\
26.7\end{array}$} \\
\hline Prescriptions dispensed per week & $<100$ & & \\
\hline & $100-500$ & 39 & 37.1 \\
\hline & $501-1000$ & 24 & 22.9 \\
\hline & $1001-1500$ & 7 & 6.7 \\
\hline & $>|50|$ & 7 & 6.7 \\
\hline \multirow[t]{3}{*}{ Place medicine information provided } & In private area & 72 & 68.6 \\
\hline & In semi-private area & 24 & 22.9 \\
\hline & In a non-private area & 9 & 8.6 \\
\hline \multirow[t]{3}{*}{ Preferred medication counselling methods } & Verbal & 15 & 14.3 \\
\hline & Written & 6 & 5.7 \\
\hline & Both verbal and written & 84 & 80 \\
\hline \multirow[t]{3}{*}{ Reasons for delivering verbal information only } & The pharmacy is too busy & 70 & 66.7 \\
\hline & The consumer is not interested & 22 & 21.0 \\
\hline & Verbal information is sufficient & 13 & 12.4 \\
\hline \multirow[t]{4}{*}{ Average time spent on counselling } & $<$ Iminute & 12 & 11.4 \\
\hline & $\mathrm{I}-2$ minutes & 51 & 48.6 \\
\hline & $2-5$ minutes & 26 & 24.8 \\
\hline & $>5$ minutes & 16 & 15.2 \\
\hline
\end{tabular}

prescriptions dispensed per week, counseling area, preferred counseling methods, and reason for verbal counseling only were found to be statistically significant

Table 3 The List of Questions Used in the Study

\begin{tabular}{|l|l|}
\hline No. & Questions \\
\hline Q1 & $\begin{array}{l}\text { Average time in minutes spent for provision of verbal } \\
\text { information per prescription }\end{array}$ \\
\hline Q2 & Explaining the purpose/importance of counseling to patients \\
\hline Q3 & $\begin{array}{l}\text { Ask the patient what the prescriber has told them about drug } \\
\text { and how they understood }\end{array}$ \\
\hline Q4 & $\begin{array}{l}\text { Ask patients if they have a problem in taking drugs as } \\
\text { prescribed }\end{array}$ \\
\hline Q5 & $\begin{array}{l}\text { Tell the patient when due back to refill and number of fills } \\
\text { needed when necessary }\end{array}$ \\
\hline Q6 & Emphasize the benefits of the medicine \\
\hline Q7 & Ask a woman if she is pregnant or not \\
\hline Q8 & Explain what if he/she misses a dose \\
\hline Q9 & $\begin{array}{l}\text { Listen to patient carefully and respond with appropriate } \\
\text { empathy }\end{array}$ \\
\hline Q10 & Ask patient if they any concern or question \\
\hline Q11 & Ask the patient if they have time to discuss \\
\hline
\end{tabular}

Table 4 Basic Drug Information Delivered to the Patients by Pharmacy Professionals in Drug Retail Outlets

\begin{tabular}{|l|c|c|c|}
\hline $\begin{array}{l}\text { Basic Drug } \\
\text { Information }\end{array}$ & $\begin{array}{c}\text { Observed } \\
\text { Outcome }\end{array}$ & Frequency & Percent \\
\hline Q2 & Yes & 90 & 85.7 \\
& No & 15 & 14.3 \\
\hline Q3 & Yes & 91 & 86.7 \\
& No & 14 & 13.3 \\
\hline Q4 & Yes & 88 & 83.8 \\
& No & 17 & 16.2 \\
\hline Q5 & Yes & 88 & 83.8 \\
& No & 17 & 16.2 \\
\hline Q6 & Yes & 94 & 89.5 \\
& No & 11 & 10.5 \\
\hline Q7 & Yes & 96 & 91.4 \\
& No & 9 & 8.6 \\
\hline Q8 & Yes & 90 & 85.7 \\
& No & 15 & 14.3 \\
\hline Q9 & Yes & 100 & 95.2 \\
& No & 5 & 4.8 \\
\hline Q10 & Nos & 90 & 85.7 \\
& No & 15 & 14.3 \\
\hline Q11 & 90 & 85.7 \\
& Yes & 15 & 14.3 \\
\hline
\end{tabular}


Table 5 Components of Counseling Practice Among Pharmacy Professionals in Medicine Retail Outlets of Bench-Sheko Zone

\begin{tabular}{|c|c|c|c|c|c|}
\hline Components of Counselling & Always N (\%) & Often $\mathbf{N}(\%)$ & Sometimes N (\%) & Rarely N (\%) & Never $\mathbf{N}(\%)$ \\
\hline Name of the drug & $56(53.3)$ & $12(11.4)$ & $25(23.8)$ & $7(6.7)$ & $5(4.8)$ \\
\hline Frequency administration & $90(85.7)$ & $2(1.9)$ & $7(6.7)$ & $3(2.9)$ & $3(2.9)$ \\
\hline Proper storage condition & $71(67.6)$ & II (I0.5) & $21(20)$ & $\mathrm{I}(\mathrm{I})$ & $\mathrm{I}(\mathrm{I})$ \\
\hline Drug interaction & $45(42.9)$ & $12(11.4)$ & $25(23.8)$ & $15(14.3)$ & $8(7.6)$ \\
\hline Dosage form & $70(66.7)$ & $5(4.8)$ & $20(19)$ & $6(5.7)$ & $4(3.8)$ \\
\hline Adverse drug reaction & $27(25.7)$ & $14(13.3)$ & $40(38.1)$ & $19(18.1)$ & $5(4.8)$ \\
\hline Dose & $86(81.9)$ & $4(3.8)$ & $13(12.4)$ & $\mathrm{I}(\mathrm{I})$ & $\mathrm{I}(\mathrm{I})$ \\
\hline Duration of treatment & $90(85.7)$ & $2(1.9)$ & $9(8.6)$ & $3(2.9)$ & I (I) \\
\hline Contraindication & $55(52.4)$ & $20(19)$ & $14(13.3)$ & $14(13.3)$ & $2(1.9)$ \\
\hline
\end{tabular}

Table 6 Conditions Given Special Attention During Medication Counselling by Pharmacy Professionals

\begin{tabular}{|c|c|c|c|}
\hline \multicolumn{2}{|l|}{ Conditions } & \multirow{2}{*}{$\begin{array}{l}\text { Frequency } \\
35\end{array}$} & \multirow{2}{*}{$\begin{array}{r}\text { Percent } \\
33.3\end{array}$} \\
\hline Patients given special attention for counselling & Pregnant & & \\
\hline & Epileptic patients & 5 & 4.8 \\
\hline & Terminally ill & 7 & 6.7 \\
\hline & Asthmatic & 13 & 12.4 \\
\hline & Diabetes mellitus & 17 & 16.2 \\
\hline & Tuberculosis & 6 & 5.7 \\
\hline & Hypertensive & 13 & 12.4 \\
\hline & Patients taking drugs which alcohol is contraindicated & 5 & 4.8 \\
\hline & Patients taking anticoagulants & 4 & 3.8 \\
\hline \multirow[t]{5}{*}{ Additional information for patients taking drugs } & Drugs under active surveillance by EFDA* & 14 & 13.3 \\
\hline & Drugs with prominent side effect & 37 & 35.2 \\
\hline & Drugs with additional warning label & 21 & 20.0 \\
\hline & Drugs with special storage conditions & 26 & 24.8 \\
\hline & Drugs with complicated direction & 7 & 6.7 \\
\hline
\end{tabular}

Abbreviation: *EFDA, Ethiopian Food and Drug Administration.

predictors of component of counseling practice in this study. Pharmacy professionals' age was significant on components of counseling practice as on mentioning the name of drugs during dispensing the medication $(\mathrm{p}=0.000)$, the route of administration $(\mathrm{p}=0.000)$, a drug dose $(\mathrm{p}=0.003)$, frequency of drug administration $(\mathrm{p}=0.016)$, proper medicine storage $(\mathrm{p}=0.024)$, type of dosage form $(\mathrm{p}=0.025)$, and duration of treatment $(\mathrm{p}=0.012)$. In comparison with the other age groups, an age greater than 40 years was significant on components of counseling practice $(\mathrm{p}=0.001)$ as a factor associated with penurious counseling practice than the other groups (Table 7).The post hoc test revealed that a significant difference was observed between participants who spent time in medicine retail outlets on components of counseling in delivering the name of the drug, route of administration of a drug, dose of a drug, frequency of administration of a drug, proper storage of drug, drug interaction, contraindication, type of dosage form, adverse effect of drug and duration treatment with a p-value of $0.000,0.000,0.004,0.019,0.000,0.017,0.000,0.001$, 0.000 and 0.000 respectively. ANOVA between the groups showed that professionals who spent less than 28 hours had significant impact on components of counseling compared to others classes of spent time. A significant difference was observed in the number of prescriptions dispensed per week for professionals dispensing prescriptions greater than 1501 in providing information about the route of drug administration ( $\mathrm{p}=0.000)$, a dose of the drug $(\mathrm{p}=0.005)$, frequency of administration $(\mathrm{p}=0.038)$, proper storage of medicine $(\mathrm{p}=0.000)$, drug interaction $(\mathrm{p}=0.000)$, contraindication $(\mathrm{p}=0.000)$, adverse effect of drug $(p=0.022)$ and duration of treatment $(p=0.000)$. In comparison with the other groups on experience, participants with 


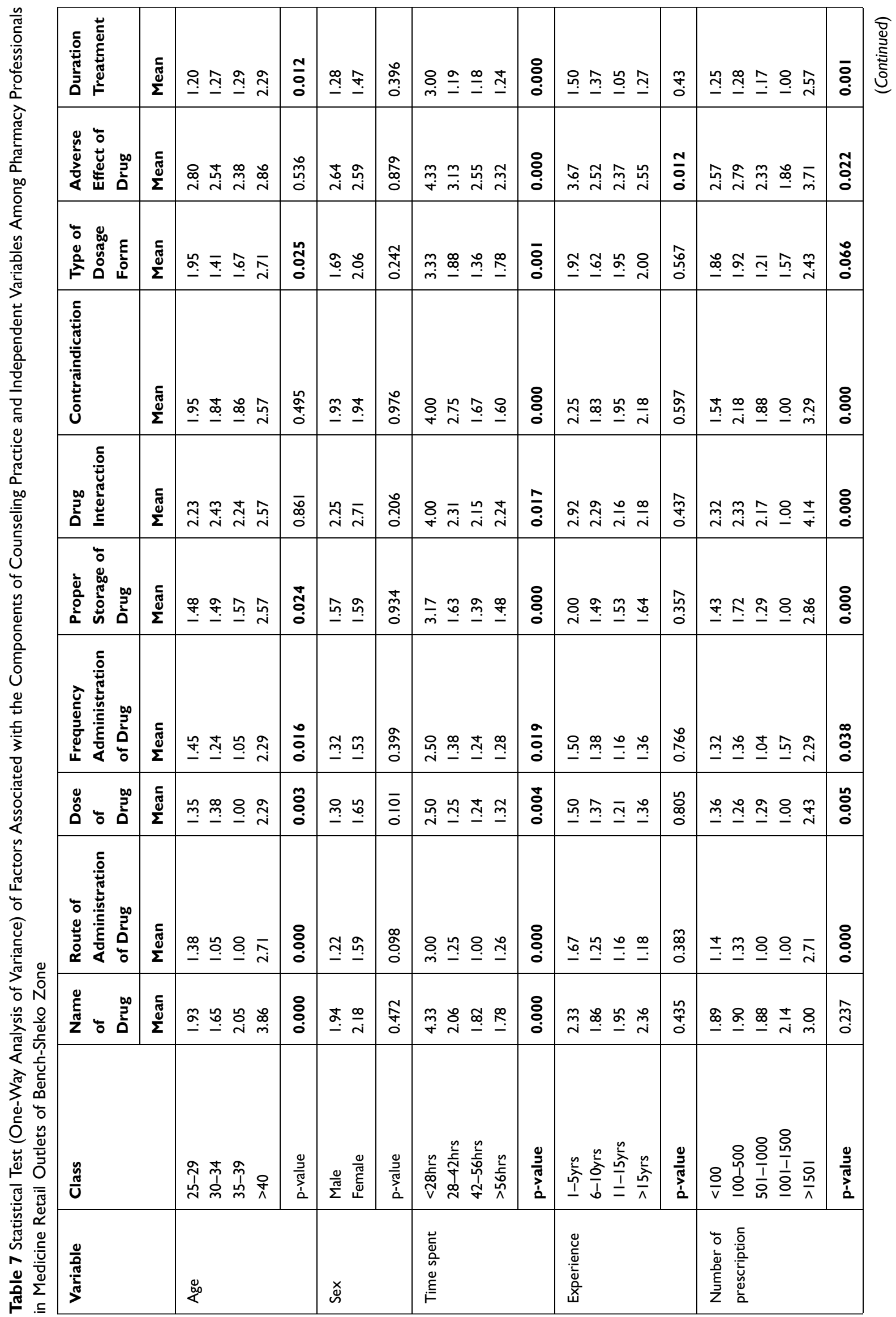




\begin{tabular}{|c|c|c|c|c|c|c|c|c|}
\hline 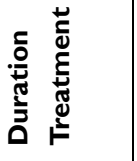 & 胥 & $\overline{\underline{I}} \overline{\underline{I}} \stackrel{+}{\mathrm{i}}$ & : & $\stackrel{\circ}{\stackrel{m}{m} \stackrel{m}{̣}}$ & Jo & $\stackrel{m}{=} \stackrel{m}{\underline{m}}$ & $\bar{m}$ & $\stackrel{\circ}{0}$ \\
\hline 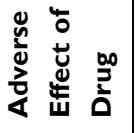 & 胥 & $\stackrel{\circ}{\text { i⿱ }} \stackrel{\infty}{\stackrel{\infty}{~} \underset{m}{m}}$ & $\frac{0}{1}$ & 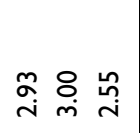 & $\underset{\substack{\infty \\
m}}{0}$ & ì & $\underset{i}{i}$ & 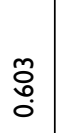 \\
\hline 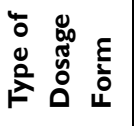 & 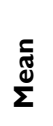 & 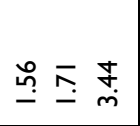 & : & 공 $\underset{\sim}{\stackrel{m}{i}} \stackrel{m}{=}$ & $\frac{\tilde{0}}{0}$ & 촌 운 & $\stackrel{\overbrace{}}{i}$ & ণัণ \\
\hline 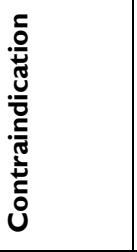 & 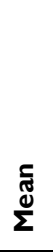 & œ® & ণ্ণি & 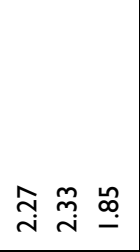 & 恕 & $\stackrel{\circ}{\underline{9}}$ & $\stackrel{\infty}{\circ}$ & $\begin{array}{l}\infty \\
\infty \\
0\end{array}$ \\
\hline 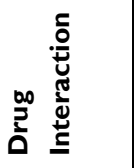 & $\frac{\tilde{\Phi}}{\Sigma}$ & 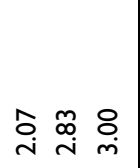 & $\frac{n}{0}$ & 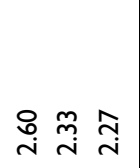 & 。ั & $\stackrel{\infty}{i} \stackrel{\circ}{\stackrel{\infty}{-}}$ & $\stackrel{\text { ָे }}{\sim}$ & م゚ \\
\hline 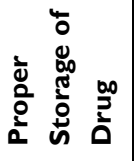 & 胥 & 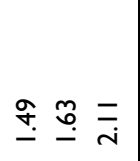 & $\frac{\pi}{0}$ & 엄 $\stackrel{m}{\underline{m}}$ & $\frac{\hat{I}}{0}$ & 守. 色 & $\frac{n}{i}$ & ?ợ \\
\hline 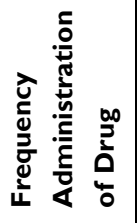 & 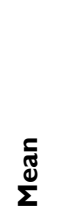 & 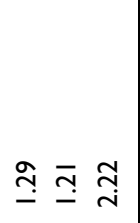 & $\frac{1}{0}$ & 安 $\stackrel{m}{=} \stackrel{m}{=}$ & $\begin{array}{l}\bar{\infty} \\
\infty \\
0 \\
0\end{array}$ & $\stackrel{m}{\underline{m}}$ & 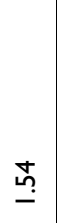 & $\begin{array}{l}\bar{n} \\
\hat{o}\end{array}$ \\
\hline 岕 & $\stackrel{\tilde{ల}}{\Sigma}$ & 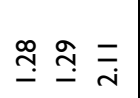 & $\frac{1}{0}$ & 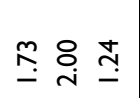 & $\overline{0}$ & $\stackrel{m}{\dddot{m}} \stackrel{\dddot{m}}{\underline{9}}$ & 菅 & 嵌 \\
\hline 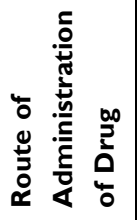 & 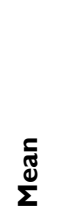 & $\cong \overline{\underline{M}} \stackrel{m}{\mathrm{~N}}$ & ষ̊̀ & ํํํ & $\frac{\kappa}{\sigma}$ & 꼬 꼬 & ọ & $\frac{a}{0}$ \\
\hline 胥 & 尔 & 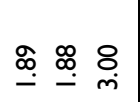 & $\stackrel{\dddot{0}}{0}$ & $\stackrel{m}{i} \bar{i} \stackrel{\circ}{i}$ & $\stackrel{\text { I̊ }}{\circ}$ & 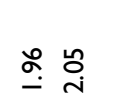 & $\underset{\text { i }}{ }$ & ڤัم \\
\hline$\frac{\tilde{\pi}}{U}$ & & 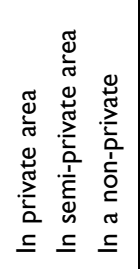 & 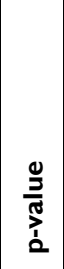 & 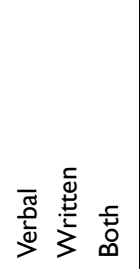 & $\frac{\mathscr{0}}{\frac{\partial}{\pi}}$ & 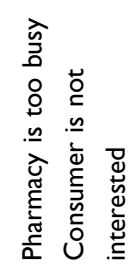 & & 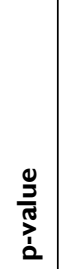 \\
\hline 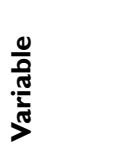 & & 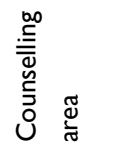 & & 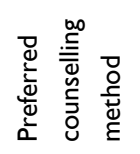 & & 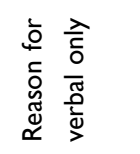 & & \\
\hline
\end{tabular}


5-10 years of experience had significance $(\mathrm{p}=0.014)$ on adverse drug effects. The Counseling area, particularly in the non-private counseling area, also had significance in the name of a drug at $(\mathrm{p}=0.03)$, route of administration $(\mathrm{p}=0.000)$, a dose of the drug $(\mathrm{p}=0.012)$, frequency of administration $(\mathrm{p}=0.012)$, types of the dosage form $(0.000)$ and duration of treatment $(\mathrm{p}=0.000)$. Preferred counseling method had a significant effect on both verbal and written counseling methods on dose of drug (0.011) and duration of treatment $(\mathrm{p}=0.044$. Reasons for preferring the oral counseling method only, in which verbal information was believed to be sufficient, had a significant association with proper storage of drug $(\mathrm{p}=0.043)$ and duration of treatment $(\mathrm{p}=0.000)$.

The difference in respondents' ages, years of experience, and time spent in medicine retail outlets, number of prescriptions dispensed per week, counseling area and preferred counseling methods, and reason for verbal counseling only were found to be statistically significant predictors of counseling practice activities in this study (Table 8). As a result of the age of pharmacy professionals showed a significant association in age greater than 40 years $(\mathrm{p}=0.017)$, overall pharmacy professionals' age showed significant impact on an average time in minutes spent for provision of verbal information per prescription $(\mathrm{p}=0.009)$, asking the patient what the prescriber has told them about drug and how they understood $(\mathrm{p}=0.009)$, asking patients if they have a problem in taking drugs as prescribed $(p=0.034)$ emphasize the benefits of medicine $(\mathrm{p}=0.000)$, ask if the woman is pregnant or not $(\mathrm{p}=0.008)$, listen to patients carefully and respond with empathy $(\mathrm{p}=0.000)$, ask the patient if they had any concern or question $(\mathrm{p}=0.039)$ and ask the patient if they have time to discuss $(\mathrm{p}=0.004)$. The average time spent in medicine retail outlets showed a significant difference in professionals who spent less than 28 hours on explaining the purpose to patients $(\mathrm{p}=0.001)$, asking the patient what the prescriber had told them about the drug and how they understood $(\mathrm{p}=0.000)$, telling the patient when it was due back for refill and the number of fills needed when necessary $(p=0.000)$, emphasizing the benefits of the drug $(\mathrm{p}=0.000)$ and ask a woman if she is pregnant or not $(\mathrm{p}=0.000)$. Professionals with $1-5$ years of experience were significantly more likely to emphasize the benefits of the medicine $(\mathrm{p}=0.028)$, explain what happens if he/she misses a dose $(\mathrm{p}=0.025)$, and ask the patient if they have time to discuss $(\mathrm{p}=0.031)$. Prescriptions dispensed in excess of 1501 showed a significant difference in asking the patient what the prescriber had told them about the drug and how they understood $(\mathrm{p}=0.002)$, asking if the woman is pregnant or not $(\mathrm{p}=0.015)$, explaining what if he/she misses a dose $(\mathrm{p}=0.000)$, listening to the patient carefully and responding with empathy $(\mathrm{p}=0.000)$, and asking the patient if they have time to discuss it $(\mathrm{p}=0.000)$.

Non-private counseling area was associated with an average time of counseling per prescription $(\mathrm{p}=0.02)$, asking the patient what the prescriber had told them about the drug and how they understood $(\mathrm{p}=0.014)$, asking if the woman was pregnant or not $(\mathrm{p}=0.019)$, and listening to the patient carefully and responding with empathy $(\mathrm{p}=0.013)$.

Preferred verbal counseling only, with significant differences on pharmacy being too busy $(p=0.035)$ and explaining what happens if he/she misses a dose $(p=0.011)$, as well as sufficient verbal information on asking if the woman is pregnant or not $(\mathrm{p}=0.000)$.

\section{Discussion}

This survey is a representative sample of a specific population designed to gather data for the assessment of counseling practice and factors related to counseling practice among pharmacy professionals working in medicine retail outlets in the Bench-Sheko zone. The most common drug information offered by pharmacy personnel to patients was frequency of use, according to the current survey. The most common drug information given by pharmacy professionals to patients was frequency of administration $(90 \%)$, duration of therapy (90\%), and unit dose dispensed $(86 \%)$ in the current study, which is similar to findings from a study conducted in Bahir Dar, Northwest Ethiopia, which revealed $96 \%, 74 \%$, and $99.2 \%$, respectively. ${ }^{7}$ This is greater than the Mekele city report, which shows $79 \%$, $62 \%$, and $65 \%$. The explanation for these disparities could be related to changes in the research population and data collection methods. The current study was an observational study similar to study conducted in Bahir Dar city, ${ }^{7}$ and the study in Mekele was conducted using selfadministered questionnaires, with data collected as claimed by pharmacy professionals. ${ }^{16}$ This study revealed that $90 \%$ of participants stated that they always tell what to do if a patient misses a dose, whereas reports from Bahir Dar and Mekele cities revealed $7.8 \%$ and $13 \%$, respectively. ${ }^{5}$ This disparity could be explained by contextual differences in the study settings and populations studied in the two research.

Although in a study conducted in India, $73.02 \%$ of pharmacists recommend separate patient counseling cabins 
Table 8 Statistical Test (One-Way Analysis of Variance) of Factors Associated with the Activities of Counseling Practice and Independent Variables Among Pharmacy Professionals in Medicine Retail Outlets of Bench-Sheko Zone

\begin{tabular}{|c|c|c|c|c|c|c|c|c|c|c|c|c|}
\hline \multirow[t]{2}{*}{ Variables } & \multirow[t]{2}{*}{ Class } & QI & Q2 & Q3 & Q4 & Q5 & Q6 & Q7 & Q8 & Q9 & Q10 & QII \\
\hline & & Mean & Mean & Mean & Mean & Mean & Mean & Mean & Mean & Mean & Mean & Mean \\
\hline \multirow[t]{5}{*}{ Age } & $25-29$ & 2.38 & 1.13 & 1.03 & 1.10 & 1.18 & 1.00 & 1.05 & 1.13 & 1.00 & 1.15 & 1.10 \\
\hline & $30-34$ & 2.78 & 1.14 & 1.14 & 1.24 & 1.08 & 1.22 & 1.05 & 1.08 & 1.05 & 1.16 & 1.16 \\
\hline & $35-39$ & 2.14 & 1.10 & 1.24 & 1.05 & 1.19 & 1.00 & 1.10 & 1.19 & 1.00 & 1.00 & 1.05 \\
\hline & $>40$ & 1.86 & 1.43 & 1.43 & 1.43 & 1.43 & 1.43 & 1.43 & 1.43 & 1.43 & 1.43 & 1.57 \\
\hline & p-value & 0.009 & 0.162 & 0.009 & 0.034 & 0.133 & 0.000 & 0.008 & 0.098 & 0.000 & 0.039 & 0.004 \\
\hline \multirow[t]{3}{*}{ Sex } & Male & 2.49 & 1.13 & 1.11 & 1.17 & 1.16 & 1.08 & 1.08 & 1.11 & 1.03 & 1.14 & 1.14 \\
\hline & Female & 2.18 & 1.24 & 1.24 & 1.12 & 1.18 & 1.24 & 1.12 & 1.29 & 1.12 & 1.18 & 1.18 \\
\hline & $\mathrm{p}$-value & 0.185 & 0.238 & 0.18 & 0.593 & 0.86 & 0.056 & 0.612 & 0.052 & 0.141 & 0.669 & 0.669 \\
\hline \multirow[t]{5}{*}{ Time spent } & $<28 \mathrm{hrs}$ & 2.00 & 1.67 & 1.67 & 1.50 & 1.67 & 1.50 & 1.67 & 1.67 & 1.50 & 1.50 & 1.50 \\
\hline & $28-42 \mathrm{hrs}$ & 2.19 & 1.06 & 1.19 & 1.19 & 1.38 & 1.00 & 1.13 & 1.25 & 1.13 & 1.38 & 1.19 \\
\hline & $42-56 \mathrm{hrs}$ & 2.64 & 1.09 & 1.09 & 1.09 & 1.09 & 1.21 & 1.06 & 1.06 & 1.00 & 1.09 & 1.12 \\
\hline & $>56 \mathrm{hrs}$ & 2.44 & 1.14 & 1.08 & 1.16 & 1.08 & 1.02 & 1.02 & 1.10 & 1.00 & 1.06 & 1.10 \\
\hline & p-value & 0.224 & 0.001 & 0.000 & 0.096 & 0.000 & 0.000 & 0.000 & 0.000 & 0.000 & 0.001 & 0.06 \\
\hline \multirow[t]{5}{*}{ Experience } & I-5yrs & 1.92 & 1.33 & 1.25 & 1.42 & 1.33 & 1.16 & 1.25 & 1.42 & 1.17 & 1.25 & 1.42 \\
\hline & $6-10 y r s$ & 2.52 & 1.14 & 1.10 & 1.13 & 1.08 & 1.33 & 1.10 & I.II & 1.03 & 1.14 & 1.10 \\
\hline & $11-15 y r s$ & 2.63 & I.II & 1.16 & 1.05 & 1.26 & 1.10 & 1.00 & 1.05 & 1.00 & 1.00 & 1.16 \\
\hline & $>15 y r s$ & 2.18 & 1.00 & 1.18 & 1.27 & 1.27 & 1.00 & 1.00 & 1.18 & 1.09 & 1.27 & 1.09 \\
\hline & p-value & 0.085 & 0.134 & 0.48 & 0.028 & $0.04 I$ & 0.028 & 0.071 & 0.025 & 0.141 & 0.123 & 0.031 \\
\hline \multirow{6}{*}{$\begin{array}{l}\text { Number of } \\
\text { prescription }\end{array}$} & $<100$ & 2.50 & 1.18 & 1.18 & 1.07 & 1.18 & 1.21 & 1.04 & 1.07 & 1.00 & 1.07 & 1.14 \\
\hline & $100-500$ & 2.46 & 1.08 & 1.10 & 1.26 & 1.13 & 1.00 & 1.08 & 1.13 & 1.05 & 1.21 & 1.15 \\
\hline & $501-1000$ & 2.33 & 1.08 & 1.00 & 1.08 & 1.13 & 1.04 & 1.08 & 1.08 & 1.00 & 1.04 & 1.00 \\
\hline & $1001-1500$ & 3.14 & 1.14 & 1.14 & 1.00 & 1.14 & 1.14 & 1.00 & 1.14 & 1.00 & 1.14 & 1.00 \\
\hline & $>|50|$ & 1.71 & 1.57 & 1.57 & 1.43 & 1.43 & 1.43 & 1.43 & 1.71 & 1.43 & 1.43 & 1.71 \\
\hline & p-value & 0.045 & 0.01 & 0.002 & 0.033 & 0.375 & 0.001 & 0.015 & 0.000 & 0.000 & 0.058 & 0.000 \\
\hline \multirow{4}{*}{$\begin{array}{l}\text { Counselling } \\
\text { area }\end{array}$} & In private area & 2.49 & 1.11 & 1.11 & 1.18 & 1.17 & 1.10 & 1.06 & 1.13 & 1.01 & 1.11 & 1.17 \\
\hline & In semi-private area & 2.58 & 1.21 & 1.08 & 1.08 & 1.13 & 1.08 & 1.08 & 1.17 & 1.08 & 1.21 & 1.04 \\
\hline & In a non-private & 1.67 & 1.22 & 1.44 & 1.22 & 1.22 & 1.22 & 1.33 & 1.22 & 1.22 & 1.22 & 1.22 \\
\hline & p-value & 0.02 & 0.395 & 0.014 & 0.476 & 0.786 & 0.484 & 0.019 & 0.69 & 0.013 & 0.395 & 0.252 \\
\hline \multirow{4}{*}{$\begin{array}{l}\text { Preferred } \\
\text { counselling } \\
\text { method }\end{array}$} & Verbal & 2.47 & 1.27 & 1.20 & 1.20 & 1.13 & 1.20 & 1.20 & 1.20 & 1.13 & 1.20 & 1.27 \\
\hline & Written & 2.50 & 1.33 & 1.17 & 1.17 & 1.33 & 1.17 & 1.17 & 1.33 & 1.17 & 1.17 & 1.17 \\
\hline & Both & 2.43 & 1.11 & 1.12 & 1.15 & 1.15 & 1.08 & 1.06 & 1.12 & 1.02 & 1.13 & 1.12 \\
\hline & $\mathrm{p}$-value & 0.974 & 0.105 & 0.683 & 0.91 & 0.499 & 0.356 & 0.158 & 0.283 & 0.069 & 0.774 & 0.324 \\
\hline \multirow{4}{*}{$\begin{array}{l}\text { Reason for } \\
\text { verbal only }\end{array}$} & Pharmacy is too busy & 2.59 & 1.09 & 1.10 & 1.13 & 1.16 & 1.11 & 1.03 & 1.07 & 1.03 & 1.13 & 1.11 \\
\hline & $\begin{array}{l}\text { Consumer is not } \\
\text { interested }\end{array}$ & 2.18 & 1.23 & 1.14 & 1.27 & 1.18 & 1.05 & 1.05 & 1.27 & 1.05 & 1.14 & 1.23 \\
\hline & Verbal sufficient & 2.08 & 1.31 & 1.31 & 1.15 & 1.15 & 1.15 & 1.46 & 1.31 & 1.15 & 1.23 & 1.15 \\
\hline & p-value & 0.05 & 0.049 & 0.131 & 0.282 & 0.961 & 0.549 & 0.000 & 0.011 & 0.153 & 0.631 & 0.422 \\
\hline
\end{tabular}

Notes: Significant at $p<0.05$; Values in bold indicate statistically significant results. 
as necessary, ${ }^{17}$ in our study only $68.6 \%$ of the professionals considered private counseling rooms. It is preferable to provide patient counseling in a separate room that ensures comfort, confidentiality, and a safe environment; that can establish a good relationship between patient and pharmacist; and that regulatory bodies ensure that all establishments follow the criteria provided for the construction of medicine retail outlets before they begin operations. It is preferred to provide patient counseling in an isolated room that ensures comfort, confidentiality, and a safe environment; that can establish a good relationship between patient and pharmacist; and it is indispensable that the regulatory bodies make sure that all the establishments are following the criteria provided to construct medicine retail outlets before launching their services. ${ }^{4}$

We found an association between components of counseling and the age of pharmacy professionals (Table 7) and also a mean difference has been observed between age groups with professionals aged greater than 40 years was statistically significant. This is in line with study conducted by Wabe et $\mathrm{al}^{5}$ and Ali et al. ${ }^{18}$ This might be because pharmacy professionals who have worked for many years in a particular setting tend to experience exhaustion and burnout from their work. It is challenging for a younger generation of pharmacists to enhance better counseling on their own. It is difficult for junior pharmacists to disrupt the pharmacy's established communication style; more likely, they will adapt to the current practice. ${ }^{19}$

We find no association between counseling components and the sex of pharmacy professionals, which is in line with the study done by Mohamed and Al-Arifi in Saudi Arabia. ${ }^{15}$ Professionals who spent less time in medicine retail outlets were significantly delivering components of counseling to their patients. Our results suggest that pharmacists whose jobs allow them some flexibility to control the pace of their work, use the skills they feel necessary to do their work, and work in environments where there is a clear understanding of the pharmacy professionals' role will be more successful at providing patient consultations. In other words, our results suggest that when pharmacy professionals cannot control the pace of their work and are not engaged in activities that utilize their cognitive skills, they perceive poorer performance providing patient consultations on new medications. ${ }^{19,20}$ This contradicts a study conducted by Gebregziabiher et al where no difference was observed during counseling practice in different age groups of the profession. This might be due to an observer bias. ${ }^{16}$
Counseling duration was measured in this study because dedicating an appropriate amount of time to providing adequate counseling about medications has been proven to be necessary for improving patient understanding and consequently achieving better therapeutic outcomes. ${ }^{21}$ However, there is no ideal amount of time to spend on counseling as it is rather dependent on various factors like patients' condition, patients' interest, as well as the pharmacist's work schedule. ${ }^{22}$

In our study, time spent on counseling had significant mean difference on independent variables like age, experience, number of prescriptions dispensed per week and counseling area as shown in Table 8 (the abbreviated terms are shown in Table 3). This study is in line with the study conducted by Alfadi et al. This may be due to a lack of continuing professional development and onthe-job training regarding the importance and skills of providing medication counselling, and it could be due to a lack of up-to-date drug information available for community pharmacists. This lack of clinical knowledge is considered by many researchers as a major obstacle that negatively affects the ability of pharmacy professionals to take enough time to provide adequate counseling to patients. ${ }^{5,21}$ This limited counseling practice could be due to other factors, including the fact that the practice of medicine in retail outlets is generally businessoriented $^{23}$ and also could be due to the heavy workload for many community pharmacists. Also, time spent on counseling may need to be longer when a patient is using any medications or has a complicated drug regimen, or when a pharmacy professional is counseling special groups like geriatrics. ${ }^{24}$

As a result of our findings, we recommend that medicine retail outlets focus on developing a strong skill development system, increasing manpower, and implementing regular monitoring for the application of dispensing ethics to improve their patient counseling practice, as well as regulatory bodies such as the Ethiopian Food and Drug Administration (EFDA). Standard criteria for patient counseling practice should be developed and implemented by health bureaus, and all pharmacy professionals should take responsibility for ensuring high-quality pharmaceutical services. We recommend that drug stores focus on developing a robust skill development system, boosting manpower, and implementing regular monitoring for the application of dispensing ethics to improve their performance. 


\section{Limitation of the Study}

The risk of observer bias was the study's main limitation. The survey team's visits were unannounced, and there was no involvement from the survey team personnel during consultations and dispensing, which reduced bias. Furthermore, because the study was cross-sectional, seasonal fluctuation was not assessed. Furthermore, some health facilities may have heard rumors about the ongoing survey and may be awaiting a visit from the researcher and data collectors. This may have resulted in a better outcome than would have been the case otherwise.

\section{Conclusion}

According to World Health Organization drug use indicators, patient counseling is a mandatory patient care activity that should be performed in a dispensary. Counseling is still underutilized in relation to what is expected, according to this study. A high patient load, a lack of a private counseling room, and a lack of experience are factors that affect counseling services. It was observed that only basic information regarding how to use the medication is provided without exerting enough effort in comprehensive patient education. Even though there is no standard for counseling time, it was also observed that the time used for counselling was sufficient to deliver the basic medication information. We found an association between counseling components and the age of pharmacy professionals, as well as a statistically significant difference between age groups with professionals older than 40 years.

\section{Abbreviations}

ANOVA, Analysis of variance; WHO, World Health Organization; COVID-19, Coronavirus Disease 2019; SPSS, Statistical Package for the Social Sciences; CP, Clinical Pharmacy; EFDA, Ethiopian Food and Drug Administration.

\section{Acknowledgment}

We extended our gratitude to all individuals who were involved in data collection and also the participants who genuinely provided us with all necessary information.

\section{Author Contributions}

All authors made significant contributions to the work reported, whether in the conception, study design, execution, data acquisition, analysis, and interpretation, or all of these areas; actively participated in drafting, rewriting, or critically reviewing the article; gave final approval of the version to be published; agreed on the journal to which the article was submitted; and agreed on the final version to be published.

\section{Disclosure}

The authors declare that they have no competing interests.

\section{References}

1. Svarstad BL, Bultman DC, Mount JK. Patient counseling provided in community pharmacies: effects of state regulation, pharmacist age, and busyness. J Am Pharm Assoc. 2004;44(1):22-29. doi:10.1331/ 154434504322713192

2. Puspitasari HP, Krass I, Krass I. How do Australian metropolitan and rural pharmacists counsel consumers with prescriptions? Pharm World Sci. 2009;31(3):394-405. doi:10.1007/s11096-009-9289-9

3. Urbanek K. Medication Errors in intravenous drug preparation and administration: a nursing and care medication errors in intravenous drug preparation and administration: a brief review. J Nurs Care. 2017;4(5). doi:10.4172/2167-1168.1000285

4. Belay YB, Kassa TT, Welie AG, Alemayehu MS, Dinkashe FT. Assessment of counseling practice in medicine retail outlets in Mekelle City, Northern Ethiopia. Risk Manag Healthc Policy. 2017;10:137-146. doi:10.2147/RMHP.S138300

5. Wabe NT, Raju NJ, Angamo MT. Knowledge, attitude and practice of patient medication counseling among drug dispensers in North West Ethiopia. J Appl Pharm Sci. 2011;01(7):85-90.

6. Athiyah U, Hermansyah A, Nugaheni G, Zairina E, Utami W, Hermansya A. Assessment of pharmacists ' knowledge, attitude and practice in chain community pharmacies towards their current function and performance in Indonesia. Pharm Pract (Granada). 2019;17 (3):1-7. doi:10.18549/PharmPract.2019.3.1518

7. Nigussie WD. Patient counselling at dispensing of medicines in health care facility outpatient pharmacies of Bahir Dar city, Northwest Ethiopia. Sci J Public Health. 2014;2(2):126-134.

8. Aaltonen SE, Laine NP, Volmer D, et al. Barriers to medication counselling for people with mental health disorders: a Six Country Study. Pharm Pract (Granada). 2010;8(2):122-131. doi:10.4321/ S1886-36552010000200007

9. Workye M, Admasu S, Abura T, Belete Y, Getaye Y. Clients ' expectations from and satisfaction with medicine retail outlets in Gondar Town, Northwestern Ethiopia: a Cross-Sectional Study. Integr Pharm Res Pract. 2015;4:1-12.

10. Palaian S, Emirates UA, Prabhu M. Patient counseling by pharmacist $-\mathrm{a}$ focus on chronic illness review patient counseling by pharmacist -a focus on chronic illness. Pak J Pharm Sci. 2006;19 (February):62-65.

11. World Health Organization. The world medicines situation. Geneva, Switzerland: World Health Organization; 2004. Available from: http:// apps.who.int/medicinedocs/es/d/Js6160e/. Accessed August 11, 2021.

12. Aji MA, Usman H, Suberu O. Assessment of knowledge, attitude and practice of community pharmacists towards pharmaceutical care in Kaduna State, Nigeria. Int J Pharm Teach Pract. 2014;5(2):972-976.

13. Alaqeel S, Abanmy NO. Counselling practices in community pharmacies in Riyadh, Saudi Arabia: a Cross-Sectional Study. BMC Health Serv Res. 2015;1-9. doi:10.1186/s12913-015-1220-6

14. Yang S, Kim D, Choi HJ, Chang MJ. A comparison of patients' and pharmacists ' satisfaction with medication counseling provided by community pharmacies: a cross-sectional survey. BMC Health Serv Res. 2016;16:131. doi:10.1186/s12913-016-1374-x

15. Al-Arifi MN. Patients' perception, views and satisfaction with pharmacists' role as health care provider in community pharmacy setting at Riyadh, Saudi Arabia. Saudi Pharm J. 2012;20(4):323-330. doi:10.1016/j.jsps.2012.05.007 
16. Gebregziabiher A, Dinkashe FT, Welie AG, Alemayehu MS, Dinkashe FT. Assessment of counseling practice in medicine retail outlets in Mekelle City, Northern Ethiopia. Risk Manag Healthc Policy. 2017;10:137-146.

17. Dol HS, Jadhav SS, Pisal MA, Shaikh SK, Shinde VR. Emerging trends in patient counselling: current scenario. Int J Pharm Pharm Sci. 2015;7(10):10-13.

18. Ali S, Shimels T, Bilal AI. Assessment of patient counseling on dispensing of medicines in outpatient pharmacy of Tikur-Anbessa Specialized Hospital, Ethiopia. Ethiop J Health Sci. 2019;29 (6):727-736.

19. Vainio KK, Airaksinen MSA, Hyykky TT, Enlund KH. Effect of therapeutic class on counseling in community pharmacies. Ann Pharmacother. 2002;36(5):781-786. doi:10.1345/aph.1A374

20. Chui MA, Mott DA. Community pharmacists' subjective workload and perceived task performance: a human factors approach. $\mathrm{J} \mathrm{Am}$ Pharm Assoc. 2012;52(6):e153-e160. doi:10.1331/JAPhA.20 12.11135
21. Alfadl AA, Alrasheedy AA, Alhassun MS. Evaluation of medication counseling practice at community pharmacies in Qassim region, Saudi Arabia. Saudi Pharm J. 2018;26(2):258-262. doi:10.1016/j. jsps.2017.12.002

22. Mináriková D, Fazekaš T, Minárik P, Jurišová E. Assessment of patient counselling on the common cold treatment at Slovak community pharmacies using mystery shopping. Saudi Pharm J. 2019;27 (4):574-583. doi:10.1016/j.jsps.2019.02.005

23. Alrasheedy AA, Hassali MA, Wong ZY, Aljadhey H, Saleh Karamah AL. Pharmaceutical policy in countries with developing healthcare systems. Pharm Policy Ctries Devel Healthc Syst. 2017;1-430.

24. Kimberlin CL, Jamison AN, Linden S. Patient counseling practices in U.S. pharmacies: effects of having pharmacists hand the medication to the patient and state regulations on pharmacist counseling. $J \mathrm{Am}$ Pharm Assoc. 2011;51527-51534. doi:10.1331/JAPhA201110012

\section{Publish your work in this journal}

Pragmatic and Observational Research is an international, peerreviewed, open access journal that publishes data from studies designed to reflect more closely medical interventions in realworld clinical practice compared with classical randomized controlled trials (RCTs). The manuscript management system is completely online and includes a very quick and fair peer-review system. Visit http://www.dovepress.com/testimonials.php to read real quotes from published authors. 